\title{
The ability of surface topography postural measurements to detect cobb angle progression in adolescents with idiopathic scoliosis (AIS) and a main thoracic curve: full torso scans compared to back only parameters
}

\author{
Eric C Parent ${ }^{1 *}$, Samantha Chabot ${ }^{1}$, Lindsey Westover ${ }^{1}$, Douglas Hill ${ }^{2}$, Marc Moreau $^{2}$, Douglas Hedden², \\ Edmond Lou' ${ }^{2}$, Samer Adeeb ${ }^{1}$
}

From 11th International Conference on Conservative Management of Spinal Deformities - SOSORT 2014 Annual Meeting

Wiesbaden, Germany. 8-10 May 2014

\section{Background}

External deformity due to scoliosis can be quantified by surface topography (ST) from full-torso and back-only scans. Determining the ability of ST parameters to detect which curves remain stable is necessary to determine if ST can help reduce radiation exposure in monitoring scoliosis progression.

\section{Objective}

The study goal was to compare the ability of full-torso and back-only ST parameters to detect which curves do not progress by $>5$ (Cobb degrees) in AIS with a main thoracic curve.

\section{Design}

Prospective cohort.

\section{Methods}

We assessed 42 adolescents $(\mathrm{n}=32 \mathrm{~F}$, age $13.9 \pm 1.7 \mathrm{yrs})$ with AIS with a main thoracic curve, braced $(n=22)$ or under observation $(n=20)$, using a full-torso ST scan at baseline and $12 \pm 3$ months later. Subjects were scanned standing in a positioning frame using four laser scanners. One evaluator marked 11 landmarks. Thirty full-torso and 16 backonly parameters were extracted in Matlab by digitizing landmarks on anonymized scans presented randomly. The

${ }^{1}$ University of Alberta, Edmonton, Canada

Full list of author information is available at the end of the article absolute value of the difference between visits was quantified for ST changes because surface improvement and deterioration can occur with worsening curvatures. The area under the receiver operator characteristic curves (AUC) was used to compare the accuracy in determining which curves did not progress. 2 An AUC of 1 represents a perfect and .5 a worthless parameter.

\section{Results}

The baseline Cobb angle was $24 \pm 12$ and the mean $1-\mathrm{yr}$ change was $1.6 \pm 8.6$ (range -10;34degrees). The largest curve worsened by $>5$ degrees for 13 patients. Two fulltorso ST parameters had statistically significant ability to predict which curve remained stable. The AUC of the absolute of the change in "the 10th to 90th percentile range 3 of the angle between the principal axis of inertia of torso cross-sections and the frontal plane" 1 was 0.70 (95\% CI 0.52;0.88). The absolute change in the "transverse plane angle between the anterior superior iliac spines and the sternum" was 0.73 (95\%CI $0.58 ; 0.88)$. No back-only parameters demonstrated a significant ability to predict stable curves.

\section{Conclusion}

In patients with main thoracic curves, only full-torso ST parameters had significant ability to detect stable curves during a 1 year follow-up. Future work will determine if a 
prediction rule using ST parameters can be developed to detect stable curves and reduce radiation exposure.

\section{Authors' details}

${ }^{1}$ University of Alberta, Edmonton, Canada. ${ }^{2}$ Alberta Health Services and

University of Alberta, Edmonton, Canada.

Published: 4 December 2014

\section{References}

1. Pazos V, Cheriet F, Danserau J, Ronsky J, Zernicke RF: Eur Spine J 2007, 16(11):1882-1891.

2. Portney : Foundations of clinical research. Pearson Prentice-Halli, 32009.

3. Watkins E, Parent E, Emrani M, Hill D: Test-retest standard error of measurements for full-torso surface topography parameters obtained with the arms at 30 and 90 degrees of elevation in healthy teenagers. Scoliosis 2010, 5(Suppl1):06.

doi:10.1186/1748-7161-9-S1-010

Cite this article as: Parent et al.: The ability of surface topography postural measurements to detect cobb angle progression in adolescents with idiopathic scoliosis (AIS) and a main thoracic curve: full torso scans compared to back only parameters. Scoliosis 20149

(Suppl 1):010.

\section{Submit your next manuscript to BioMed Central} and take full advantage of:

- Convenient online submission

- Thorough peer review

- No space constraints or color figure charges

- Immediate publication on acceptance

- Inclusion in PubMed, CAS, Scopus and Google Scholar

- Research which is freely available for redistribution

Submit your manuscript at www.biomedcentral.com/submit 